\title{
To Analyze Reaction Time of Drivers Based on Drivers Characteristics- A Review
}

\author{
A.S. Dhananjay ${ }^{1}$, Sagar P. Mote $^{2}$, Suraj Prajapati ${ }^{3}$, Pradnya Chacharkar ${ }^{4}$, \\ Nishant Rana ${ }^{5}$, Vaibhav Vispute \\ ${ }^{1}$ Assistant Professor, Department of Civil Engineering, Sinhgad Academy of Engineering, India. \\ ${ }_{2,3,4,5,6}$ UG Students, Department of Civil Engineering, Sinhgad Academy of Engineering, India.
}

\begin{abstract}
Traffic related issues and road accidents are two of the major and persistent issues faced in everyday life. Traffic congestion can lead to drivers becoming frustrated and engaging road rage. Mostly these accidents mainly depend upon traffic conditions and driver behaviour. Driver's behaviour is one of the most concerned factor among this which includes aggressive or passive drivers, young inexperience drivers. The perceptual and cognitive factors involved are driver expectancy effect, glare, visibility, driver's dark adaption, road illusions \& driver's perception reaction time. The reaction time of driver is the most important factor contributing to the road accidents. The reaction time depends upon several factors such as driver characteristics, vehicle characteristics, roadway characteristics, environment characteristics etc. it also depends greatly on the type of situation, the degree of urgency, obstacles and the speed of vehicle. In our project we are going to analyse the reaction time based on driver's characteristics with the help of driving simulator, for the selected road stretch. The analysis of reaction time will help to assess the effectiveness of various measures to decrease the accident rate, thus the analysis estimates the relative safety of the selected road stretch.
\end{abstract}

Keywords: Accidents, Driver behaviour, Driving Simulator, Reaction time of Driver, Speed of Vehicle, Traffic conditions.

\section{Introduction}

Road safety is a multi-sectoral and multi-dimensional subject. It consist orderly development and management of roads provision of safer vehicles and response to road accidents. Owing to unsafe conditions on road collaborating with the reaction time of driver the rate of accidents in India has been high and increasing day by day. Some of the factors comprises of speed limit, weather conditions, movement of lane changing and driver's age, gender. Under different driving situations the value of reaction time is not constant. It can be affected by many factors such as driver's driving skill, driver's physical conditions, traffic conditions and roadway geometric features. The root cause of accidents and driver behaviour is based on the reaction time. For a dangerous situation to be perceived by a person, it takes finite amount of time that it requires an action. The combined time for a person to perceive a threat and react to is known as a perception reaction time. Determination of reaction time on field can be a risk full task to overcome these problems a driving simulator can be a safer alternative to determine the reaction time. Driving simulators emerged as a promising technology for the analysis of driving conditions and road user's behaviour in an attempt to tackle the problem of the accidents.

\section{Problems}

As per the survey conducted by government of India, it is estimated that 4.5 Lakh accidents take place every year in India [8]. Major cause of accident are Distracted driving, speeding, drunk driving, reckless driving, running red lights, unsafe lane changes, wrong-way driving \& reaction time of a driver are those of the major causes of accidents. The risk of driver being involved in a crash depends on many factors such as roadway type, environmental features, vehicle characteristics, behaviour of the driver, traffic density and flow and other road users. The road accidents and car crashes leads to severe injuries and huge loss of property. While it is not feasible or realistic for road safety authorities to legislate many of the above listed factors, it can be possible to manipulate those factors that are of a physical or static nature. That is why determination of reaction time based on behaviour of the driver; results would help to minimize it to some extent.

\section{Review on literatures}

[1] Anastasiya Shevatsova, Ivan Novikov, Alexey borovskoy [2015] conducted study on Research on influence of time of reaction of the drivers on the calculation of the capacity of the highway. They had investigate the effect of reaction time of driver on the capacity of highway and estimate the reaction time of driver and its relation with the capacity of highway. They have already been carried out study in the area throughput the site of a highway with traffic conditions, which showed that this value depends on the driver's 
reaction time. They calculate how much width the highway using various result obtained in the analysis, time value of reaction of the driver and is a direct correlation bandwidth from the time of reaction of the driver. The results obtained forcing to conclude that after taking psycho-physiological characteristics of drivers into account (response time) will have a significant effect on the throughout the various methods of organization of sections of the road network, implementation of which is used investigated the amount of bandwidth. They have done the study of values of time of reaction of the driver in various road conditions. The change in the value of the bandwidth of the road at the traffic lights regulation when different values of time of reaction of the driver. There are detail described the change in bandwidth when taking into account the extended classification of passenger vehicles. It was also revealed that the considered value is directly related to the distance of security, which in turn depends on the braking time. They have done the calculation of the capacity of the highway at different values of time of reaction of the driver. In this study they revealed that as the reaction time of driver increases required bandwidth of highway is more.

[2] Rafal S. Jurecki, Marek Jaskiewicz, Zbigniew Lozia, Piotr zdanowicz [2012] conducted study on Driver's reaction time under emergency braking a car- Research in a driving simulator. In this study they find out the reaction time of drivers of motor vehicles in case of accident risk. This study conducted on both testing track as well as in auto PW driving simulator. During testing on auto PW driving simulator pre-accident situation created and a test driver was trying to avoid a collision with an obstacle. Obstacle used by the authors are car, pedestrian, a set of tractor- trailer and create accidental situation. A test driver has been forced to perform a braking manoeuvre. In this study they tested 107 people of different age and driving experience in both testing track as well as in an auto PW driving simulator. Depends on testing results Author's observed that the quantitative similarity of the results obtained in the study of emergency braking ion both testing track and driving simulator. Also by using driving simulator, access the driver's behaviour in dangerous situations.

[3] John Olstam, Andreas Tapani [2011] conducted study on A Review of Guidelines for Applying Traffic Simulation to Level-of-service Analysis. For analyse level of service of road traffic conditions, Microscopic traffic simulation is often used. To increase usage of traffic simulation for level-of-service analysis of road traffic conditions, the authors gives guideline on how to apply and use traffic simulation models. Many countries have their own traffic simulation guidelines. This study gives a survey of the current traffic simulation guidelines in United State America, Germany, United Kingdom, Denmark and Sweden. The guidelines have been analysed with respect to the aspects covered: when to apply simulation; the workflow of a simulation study; needs of data collection; calibration and validation; design; analysis; and calculation of level-of-service measures. Guidelines discuss how to deal with calibration based on limited real world measurements.

[4] RafalJurecki, Tomasz Stanczyk [2011] has conducted study on the test methods and reaction time of drivers. In this study authors conducted three different tests in order to find out reaction time of driver. First test was conducted called psychological test in which they find out simple and complex reaction time of drivers. Simple reaction time is in the sense of while driving driver are supposed to press a key at the moment of appearance of stimuli(light), and complex reaction time is the time at which drivers has to press a key when the specific colour of light is appeared on the screen. The second Experiments on roads or test tracks studies on roads or test tracks which is largely preferred by many professionals as the best way to simulate traffic situations as well as to determining the reaction time. They were tested 30 drivers on the track, the study conducted by the authors, widely described in include a scenario in which on the track was simulated a perpendicular intrusion of car at the crossroads and find out reaction time of drivers. The third test was conducted on driving simulator in which the same situation is created as on the testing track. And examine the same previous 30 drivers on the simulator and record the reaction time. In the analysis report they found that the reaction time values achieved on simulators are smaller than which are achieved on the track and those values obtained from simple and complex reaction time are smaller than the values obtained on track.

[5] AtifMehmood and said M.Esa. [2009] has conducted study on Modelling reaction time in carfollowing behaviour based on human factors.In this study, the ADRT is defined as the time difference between the instant the driver receives the visual signal to adjust driver speed and the instant driver starts to adjust the gas input. The term (BRT) brake-reaction time is in use when the driver applied brake in response to the lead vehicle braking. BRT is defined as the time elapsed between the instant the driver receives the lead vehicle brake light signal and the moment driver touches the brake pedal. In this paper they tested 60 people (out of those 32 are male and 28 are females) on STISIM simulator and data on BRT(break reaction time) and ADRT(acceleration-deceleration reaction time) was collected and by analysing this data they found that the BRT of female is more than that of males in different scenarios (normal, surprised, stationary), And same in case of ADRT.

[6] Predrag Duric and Danka Filipovic [2007] carried study on the topic of Level of neurotic disorder among drivers causing traffic accidents. In this paper they studied human personality which determines psychological status of individual. The person who caused accidents is found around $13.3 \%$. The people who caused accidents and survived have at least one personality disorders and among them half are obsessive- 
compulsive disorders. The study group involves 30 men examines aged 28-40. In this study they divided these 30 men into two groups namely as study group and control group. In study group involves those people who caused at least one accidents and control group involves those people who have same characteristics as that of study group, without causing a single accidents. The persons having eye and hearing problems those are excluded from this investigation. Reaction time of examinees was measured by DONDERS computer program under various conditions and 3 different tasks. Investigation results in $73.33 \%$ of control group had zero neurotic disorders and in study group $1 / 3^{\text {rd }}$ of examinees had zero neurotic disorders when compare with Cornell index. Drivers having increased level of disorders have significantly more reaction time.

[7] Heikki Summala [2000] has carried out study on Break reaction time and driver behaviour analysis. In this paper he determine the brake reaction time in series of values for expected, unexpected and surprise situations, that appear to generalise large variety of driver tasks and traffic conditions. And he found that for unexpected, expected and surprise situations the break reaction times are $1.25 \mathrm{sec}, 1.0 \mathrm{sec}$ and $1.5 \mathrm{sec}$ respectively.

\section{Conclusions}

From the review of above literatures it has been observed that

1. As the reaction time of driver increases, required bandwidth of highway increases subsequently capacity of highway decreases.

2. By using driving simulator we can access the driver behaviour in dangerous situations.

3. Reaction time values achieved on simulators are smaller than which are achieved on the testing track.

4. Break reaction time and acceleration deceleration reaction time of female drivers is more than that of male drivers in different traffic situations.

5. Drivers which having increased level of neurotic disorder takes more time to react the situations.

6. Reaction time of drivers varies as per drivers behaviour and traffic conditions.

\section{References}

[1]. Anastasiya Shevtsova, Ivan Novikov, Alexey Borovskoy, "To determine methods and issues related to the determination of drivers reaction time", Transport Problems, Volume 10 Issue 3, 2015.

[2]. Jurecki R, Jaśkiewicz M, Guzek M, Lozia Z, Zdanowicz P. "Driver's reaction time under emergency braking a car - Research in a driving simulator, " Eksploatacjai Niezawodnosc - Maintenance and Reliability 2012; 14 (4): $295-301$.

[3]. Johan Olstama, Andreas Tapani, "A Review of Guidelines for Applying Traffic Simulation to Level-of-service Analysis", Procedia Social and Behavioural Sciences 16 (2011) 771-780, 6th International Symposium on Highway Capacity and Quality of Service Stockholm, Sweden June 28 - July 1, 2011

[4]. Rafał Stanisław Jurecki, Tomasz L. Stańczyk, "The test metod and the reaction time of drivers”, Eksploatacjai Niezawodnosc Maintenance and Reliability · January 2011.

[5]. Atif Mehmood and Said M. Easa, "Modelling Reaction Time in Car-Following Behaviour Based on Human Factors," World Academy of Science, Engineering and Technology International Journal of Civil, Environmental, Structural, Construction and Architectural Engineering Vol:3, No:9, 2009.

[6]. Predrag Duric, Danka Filipovic, “Level of neurotic disorders among drivers causing traffic accidents,” Med Pregl 2007; LX (78):365-371.Novi Sad: juli-avgust.

[7]. Heikki Summala University of Helsinki, "Brake Reaction Times and Driver Behaviour Analysis" Transportation Human Factors, 2(3), 217-226 Copyright (C) 2000, Lawrence Erlbaum Associates, Inc.

[8]. www.googleearth.com, http://data.gov.in/keywords/indian-road-accidents-data. 